\title{
PENJADWAL PAKAN IKAN KOI OTOMATIS Pada Kolam MENGGUNAKAN RTC DS3231
}

\author{
Feri Andriawan1) \\ 1)Program Studi Sistem Komputer Fakultas Teknologi Informasi \\ Universitas Islam Balitar Blitar \\ e-mail: feriandriawan80@gmail.com ${ }^{1)}$
}

\begin{abstract}
Abstrak : Penelitian ini bertujuan untuk membantu pembudidaya ikan memberi pakan ikan koi sesuai jadwal dengan otomatis, karena pemberian pakan yang tidak teratur akan mempengaruhi pertumbuhan dan warna yang dihasilkan oleh ikan koi. Dalam pembuatan alatpenjadwal pakan ikan koi otomatis terdapat langkah-langkah yang dilakukan seperti menentukan komponen yang digunakan,komponen tersebut diantaranya mikrokontroler Arduino Uno, sensor utrasonik HC-SR04, RTC DS3231, motor servo, dan buzzer. Membuat desain alat dan rangkaian komponen yang dilanjutkan dengan perancangan alat penjadwal pakan ikan koi otomatis.Pengujian produk dilakukan di kolam ikan koi jenis fiber, pengujian ini difokusakan pada pemberian pakan dan deteksi ketersedian pakan dalam wadah. Berdasarkan pengujian sistem secara keseluruhan, pakan diberikan sesuai jadwal yang telah diatur pada program dan alarm indikator ketersedian pakan bekerja sesuai dengan batasan yang diberikan pada program.
\end{abstract}

Kata Kunci :ATmega 328, Ikan Koi, Motor Servo, Pakan Koi Otomatis, RTC DS3231

\begin{abstract}
This research aimed to help fish farmer feed fish according to the schedule automatically, because irregular feeding will give affect the growth and color produced by koi fish. In making schedule tools for automatic koi fish feed, there were steps taken such as determining the components used, these components include the Arduino Uno microcontroller, HC-SR04 ultrasonic sensor, DS3231 RTC, servo motor, and buzzer. Make design tools and the component series, followed by the design of automatic fish feeding tools. Product testing was carried out in koi's fiber pool, this test was focused on feeding and detection of feed availability in feed containers. Based on overall system testing, feed is given according to the schedule set in the program and alarm indicators of availability of feed work according to with the limits given to the program.
\end{abstract}

Keyword :ATmega 328,Koi Fish, Servo Motor, Automatic Koi Feed, , RTC DS3231,

\section{Pendahuluan}

$\mathrm{P}$ emberian pakan merupakan hal yang penting dalam pembudidayaan ikan. Akan tetapi secara umum pemberian pakan masih dilakukan dengan cara manual yang berorientasi pada sumber daya manusia. Cara ini memiliki kekurangan yang juga berpengaruh terhadap pertumbuhan ikan seperti, kesalahan penjadwalan dan tidak terkontrolnya takaran pakan yang diberikan.

Pemberian pakan ikan koi dilakukan sebanyak 3-4 kali dalam sehari dengan takaran dan waktu yang tepat. Pemberian pakan yang terlalu sering dan berlebihan akan mempengaruhi kesehatan ikan, karena sisa makanan tersebut akan bercampur dengan kotoran sehingga menjadi amonia dan terdekomposisi menjadi nitrit yang berbahaya bagi kesehatan ikan [1]. Permasalahan ini mendasari pembuatan sebuah sistem penjadwal pakan ikan koi otomatis menggunakan RTC DS3231, untuk mengurangi kesalahan-kesalahan yang terjadi pada pemberian pakan manual.

Penelitian yang dilakukan oleh Darmawis (2017) menggunakan RTC untuk mengatur jadwal pemberian pakan, yang memberi informasi untuk mengaktifkan motor servo membuka katup pakan dan motor DC untuk melontarkan pakan ikan. Ketersedian pakan ikan dikontrol oleh sensor ultrasonik apabila pakan tinggal sedikit buzzer aktif. Dalam penelitian ini terdapat sensor $\mathrm{pH}$ yang difungsikan untuk membaca kondisi air, apabila air tidak normal maka pompa air dan solenoid valve aktif [2].

Penelitian yang dilakukan oleh peneliti diberikan batasan untuk menghindari melebarnya pembahasan. Adapun batasan yang diberikan adalah alat ini dikhususkan untuk ikan koi dengan kolam 
berukuran $2 \mathrm{mx}$ 1,5 m. Pemberian pakan dilakukan pada jam 08.00, 11.00, dan 14.00 dengan populasi ikan minimal 15 ekor maksimal 100 ekor. Pakan menggunakan pelet merk PK yang berbentuk kecil.

Pembuatan alat penjadwalan pakan ikan secara otomatis menggunakan mikrokontroler Arduino Uno. Arduino Uno merupakan pengendali mikro sigle-board yang bersifat open source yang modul mikrokontrolernya menggunakan ATmega 328. Arduino Uno mempunyai 14 pin digital input/output dimana 6 diantaranya digunakan sebagai output PWM, 6 input analog, USB, power jack, dan tombol reset. Program Arduino Uno menggunakan bahasa $\mathrm{C} / \mathrm{C}++$ melalui software Integrated Development Enveropment (IDE) [3].

RTC DS3231 merupakan modul yang digunakan untuk mengakses data informasi kalender dan jam. Format jam dapat diatur dalam 24 jam dan 12 jam dan setiap akhir bulan, tanggal dapat disesuaikan secara otomatis. Untuk berkomunikasi dengan clock/RAM DS3231 menggunakan 2 saluran yakni saluran SCL (Serial Clock), saluran SDA (Serial I/O data) [4].

Motor servo merupakan perangkat aktuator putar yang dirancang dengan sistem kontrol umpan balik loop tertutup. Sistem ini berfungsi mengontrol gerakan dan posisi terakhir poros motor servo, motor servo mampu berputar dari sudut $0^{\circ}-180^{\circ}$. Untuk motor servo tipe SG90 memilki batas maksimal pengakatan beban $1,8 \mathrm{~kg}$ dan memiliki 3 pin yakni pin GND, VCC, dan pin pulsa [5].

Sensor ultrasonik HC-SR04 adalah sensor $40 \mathrm{KHz}$ yang digunakan untuk mengukur jarak antara objek (penghalang) dengan sensor. Dalam rangkaian sensor memiliki 2 komponen yang berfungsi sebagai transmitter(pemantul) dan receiver(penerima). Sensor ini memiliki ketelitian $0,3 \mathrm{~cm}$ dengan jarak minimal pengukuran $2 \mathrm{~cm}$ dan maksimal $400 \mathrm{~cm}$ [6].

Buzzer merupakan komponen indikator yang merubah energi listrik menjadi suara. Suara ini dihasilkan oleh osilator internal dengan frekuensi kerja sebesar $400 \mathrm{~Hz}$. Buzzer dapat bekerja pada tegangan $6 \mathrm{~V}$ sampai dengan $12 \mathrm{~V}$ dengan arus sebesar $25 \mathrm{~mA}$ [2].

\section{Metode Penelitian}

Metode pada penelitian ini menggunakan Research and Development (Penelitian dan pengembangan). Research and Development (R\&D) merupakan penelitian yang hasilnya digunakan untuk membantu pelaksanaan pekerjaan. Dengan dibantu produk yang telah dihasilkan maka akan semakin produktif, efektif, dan efisien. Metode penelitian R\&D digunakan untuk menyusun STD (Skripsi, Tesis, dan Disertasi) apabila peneliti akan menguji dan mengembangkan produk tertentu yang sudah ada, serta menemukan produk yang lebih efektif, baru dan original [7].

3.1 Potensi dan Masalah

Berdasarkan studi literatur dan wawancara,didapatkan permasalahan pada pemberian pakan ikan koi yang masih manual. Karena memiliki beberapa kekurangan seperti takaran pakan dan waktu pemberian pakan yang tidak tepat, ini akan mempengaruhi pertumbuhan ikan dan warna ikan koi. Didasari oleh kebutuhan tersebut, peneliti membuat alat pakan ikan koi otomatis menggunakan Arduino Uno sebagai pengontrol sistem dan RTC DS3231 untuk mengatur jadwal keluarnya pakan.

3.2 Pengumpulan Data

Pengumpulan data sangat erat hubunganya dengan masalah penelitian yang akan dipecahkan,berikut teknik yang dilakukan untuk mengumpulkan data :

A. Penelitian Langsung merupakan studi lapangan untuk memperoleh data-data yang diperlukan dalam penyusunan tugas akhir. Teknik yang digunakan diantaranya, observasi adalah mengamati dan mempelajari tentang budidaya ikan koi serta mempelajari alat-alat yang diperlukan, wawancara merupakan teknik pengumpulan data dengan cara tanya jawab dengan pembudidaya ikan koi.

B. Studi Pustaka adalah teknik pengumpulan data dari berbagai sumber pustaka yang relevan dan berkaitan dengan masalah yang akan dibahas.

3.3 Desain Produk

Desain produk merupakan tahap awal perencanaan suatu desain alat yang akan dibuat sebelum dilakukan validasi dengan dosen ahli. Desain yang divalidasi dengan dosen ahli berupa gambar alat, 
flowchart sistem, dan blok diagram. Selain itu juga di jelaskan cara kerja beserta tahapanya dan kebutuhan alat yang diperlukan untuk merancang alat.

3.4 Validasi Desain

Validasi desain dilakukan dengan dosen pembimbing dan dosen ahli robotik. Validasi desain ini bertujuan untuk mengetahui kekurangan desain alat yang akan dibuat, untuk selanjutnya dilakukan perbaikan dan penambahan atau pengurangan. Hasil dari validasi yang dilakukan oleh peneliti didapat perbaikan beberapa letak komponen dan desain sistem pemberian pakan ikan koi otomatis.

3.5 Perbaikan desain

Berdasarkan validasi desain dengan dosen ahli, dilakukan perbaikan pada desain alat dan juga sistem sesuai dengan saran dosen ahli. Pertama dilakukan perbaikan pada blok diagram, karena alur pada desain sebelumnya kurang jelas sehingga sulit dipahami. selain itu keterangan dari blok diagram tidak sinkron dengan desain. Berikutnya dilakukan perbaikan pada flowchart sistem dan desain alat, pada flowchart sistem terdapat perbaikan di bagian alur sistem dan pada desain alat hanya perlu ditambahkan komponen yang belum dimasukan pada desain.

Blok diagram berfungsi untuk menunjukan komponen yang menjadi input-an sistem, pengontrol sistem, dan komponen yang menjadi output-an sistem.Alat dan bahan yang digunakan secara umum didesain seperti gambar 1 .

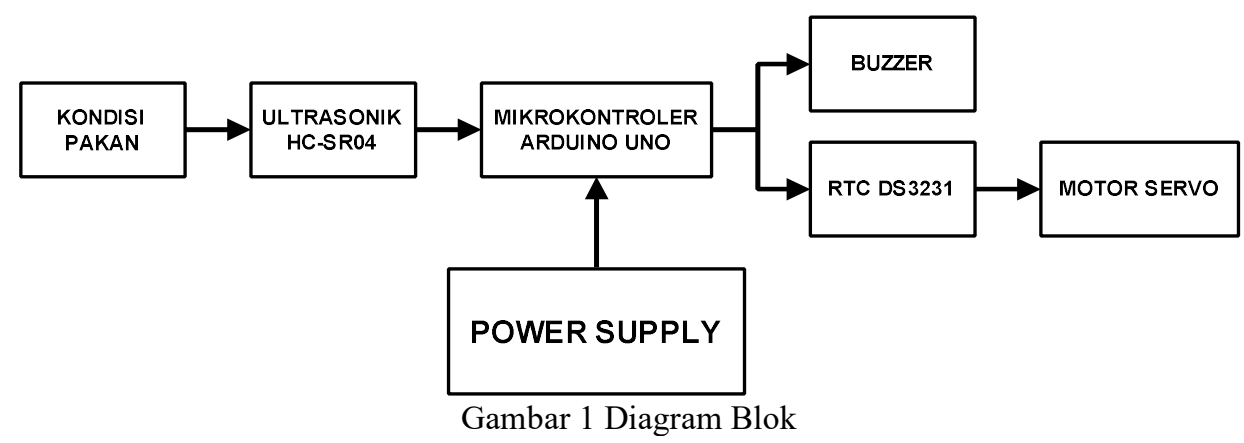

Prinsip kerja berdasar diagram blok pada gambar 1 adalah ultrasonik mengecek persediaan pakan ikan koi dalam wadah. Berikutnya ultrasonik memberi input-an ke mikrokontroler untuk melakukan langkah berikutnya, apabila persedian pakan tinggal sedikit buzzer akan bunyi sebaliknya jika pakan ikan dalam wadah masih banyak, mikrokontroler akan memerintahkan motor servo membuka katup berdasarkan waktu yang ditunjukan oleh RTC.

Tahapan dari kinerja sistem pemberian pakan ikan koi otomatis digambarkan oleh flowchart sistem. Gambar 2 merupakan flowchart sistem pemberian pakan ikan koi otomatis, flowchart tersebut menjelaskan proses dari kinerja pemberian pakan ikan koi otomatis. Proses tersebut dilakukan secara bertahap dari kondisi awal sampai selesai.
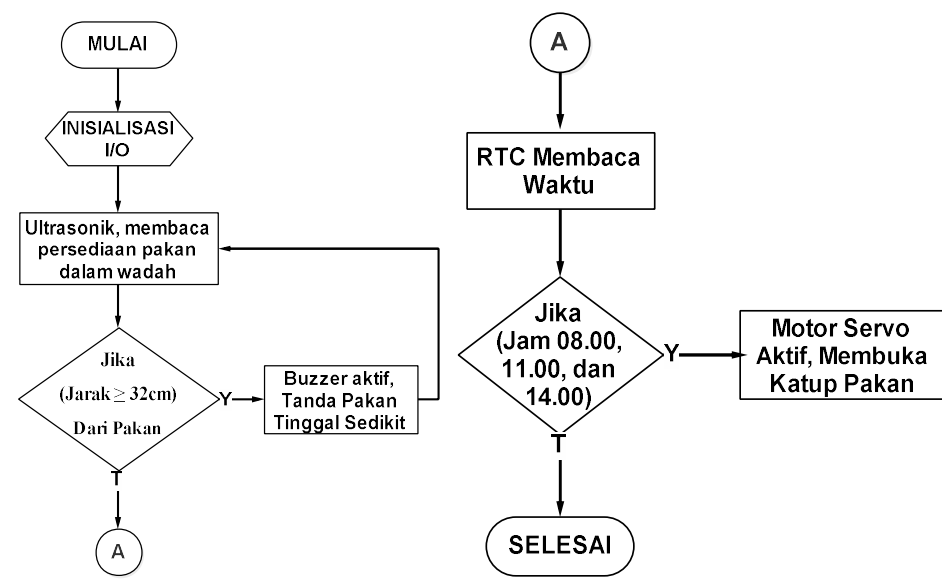

Gambar 2 Flowchart Sistem Penjadwal Pakan Ikan Otomatis 
Selain desain sistem pemberian pakan ikan koi otomatis seperti pada gambar diatas dibutuhkan juga desain alat. Pembuatan desain alat bertujuan untuk menggambarkan alat yang berupa hardware. Desain alat yang dibuat dijadikan sebagai acuan agar dapat mengurangi kesalahan perancangan alat, perancangan desain alat harus disertai ukuran alat dan komponen apa saja yang digunakan. Alat yang dibuat memiliki tinggi $40 \mathrm{~cm}$ dan lebar $20 \mathrm{~cm}^{2}$, komponen yang digunakan adalah arduino uno, RTC, motor servo, sensor ultrasonik, dan buzzer. Gambar 2 merupakan desain alat setelah dilakukan validasi desain dengan dosen ahli.

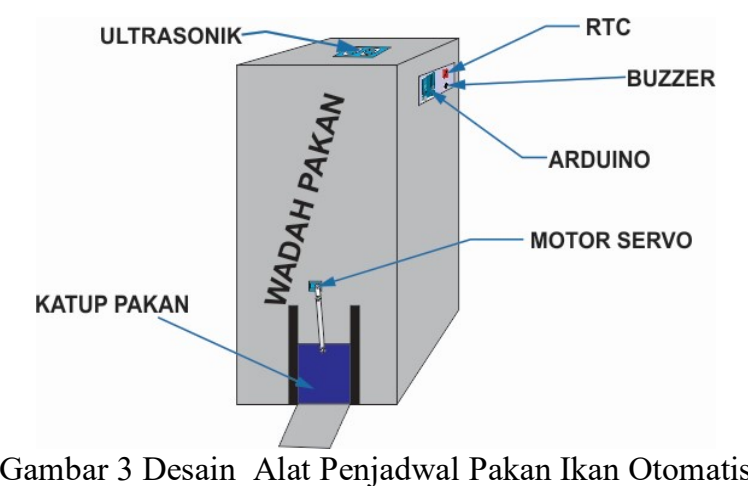

\subsection{Uji Coba Produk}

Pengujian produk dilakukan setelah pembuatan produk berdasarkan desain yang telah diuji validitasnya. Pengujian ini bertujuan untuk mengetahui kinerja alat sesuai dengan konsep yang dibuat atau tidak, serta untuk mengetahui kekurangan dari alat. Kekurangan tersebut akan akan diperbaiki pada tahap berikutnya yakni pada tahap revisi produk.

Berdasarkan pengujian produk yang dilakukan didapat permasalahan pada pintu pakan karena sering terjadi macet. Pembacaan kondisi pakan kurang stabil disebabkan letak komponen yang kurang tepat. Delay yang terlalu cepat juga turut mempengaruhi pembacaan sensor serta kinerja motor servo.

3.7 Revisi Produk

Tahap ini merupakan tahap akhir perbaikan produk dari beberapa pengujian yang dilakukan sebelumnya. Kekurangan yang didapatkan dari uji coba produk disempurnakan pada tahap ini sebelum dilakukan pengujian pemakaian alat.

3.8 Uji Coba Pemakaian

Pengujian ini dilakukan di kolam ikan hias koi dengan ukuran2 $\mathrm{m}$ x 1,5 $\mathrm{m}$ dengan populasi ikan maksimal 100 ekor. Uji coba pemakain bertujuan untuk mengetahui keefektifan pemberian pakan ikan koi secara otomatis dengan pemberian pakan secara manual. Uji coba pemakain dilakukan bersama dengan pemilik kolam ikan untuk mengetahui kekurangan alat agar dapat dikembangakan pada penelitian berikutnya. 


\subsection{Hasil Penelitian}

\section{HASIl DAN PEMBAHASAN}

Alat penjadwal pakan ikan hias koi otomatis, menggunakan komponen elektronika berukuran kecil sehingga tidak memakan banyak tempat. Perancangan wadah pakan menggunakan bahan akrilik dengan menggunkan lem $\mathrm{G}$ dan lakban sebagai perekatnya. Akrilik yang digunakan memiliki ketebalan $3 \mathrm{~mm}$, berikut alat pemberian pakan ikan hias koi otomatis :

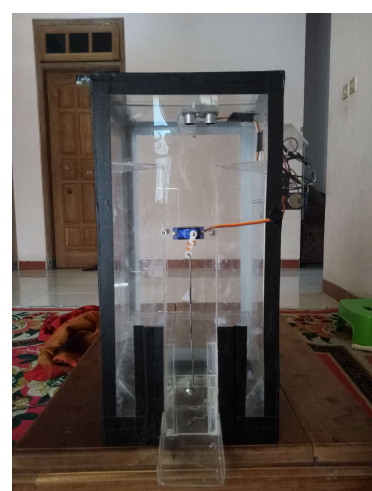

Gambar 4 Alat Pakan Ikan Koi Otomatis

\subsection{Pembahasan}

Alat penjadwal pakan ikan hias koi otomatis diberi daya $5 \mathrm{~V}$ pada mikrokontroler untuk bekerja, indikator mikrokontroler aktif ditandai dengan nyala lampu pada board arduino. Otomatisasi pemberian pakan diatur oleh RTC sebagai pengatur jadwal, pemberian pakan diatur pada jam 08.00, 11.00, dan 14.00. Untuk mengatur pemberian pakan sesuai dengan takaran, sudut putaran motor servo adalah $60^{\circ}$ dan katup pakan terbuka selama 3 detik dengan lebar $1 \mathrm{~cm}$. Persedian pakan dalam wadah dikontrol oleh sensor ultrasonik yang membaca jarak antara pakan dengan sensor apabila lebih dari $32 \mathrm{~cm}$ maka buzzer sebagai indikator akan bunyi.

A. Pengujian Struktural

Pengujian ini dilakukan untuk mengetahui apakah modul-modul elektronik suduh terhubung dengan benar atau belum sehingga sistem dapat berjalan dan berfungsi sesuai dengan yang direncanakan. Pengujian struktural dapat dilihat pada tabel 1.

Tabel 1Pengujian Struktural

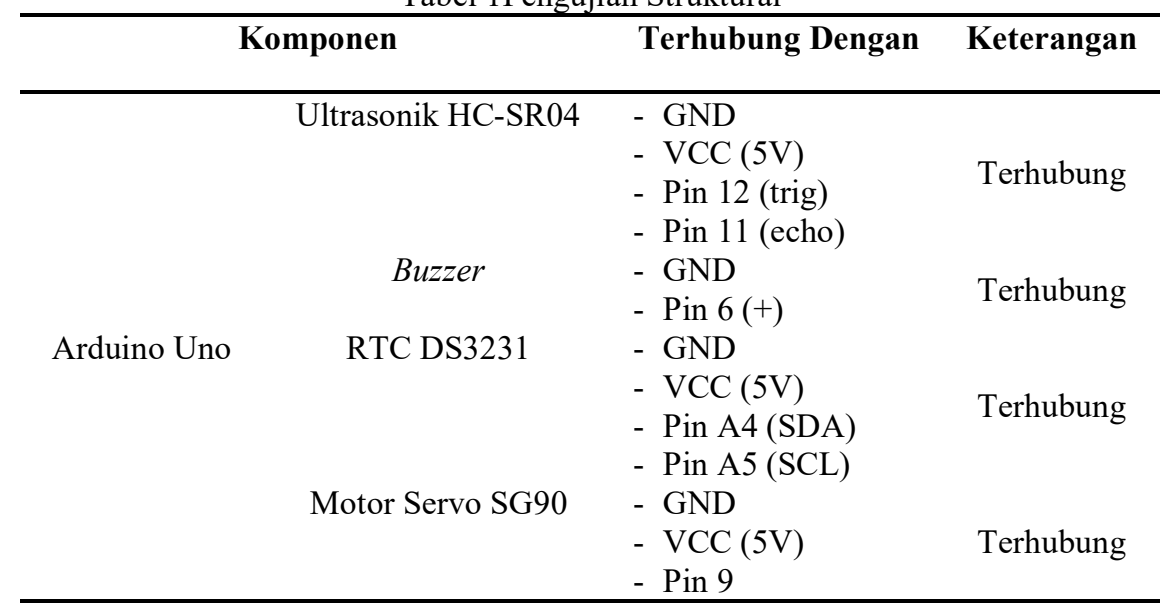


B. Pengujian Fungsional

Pengujian fungsional dilakukan pada tiap-tiap komponen yang digunakan oleh alat penjadwal pakan ikan hias koi otomatis. Fokus pengujian ini adalah mengukur tegangan yang mengalir pada tiap-tiap komponen sesuai dengan daya yang dibutuhkan oleh komponen tersebut atau tidak.

Tabel 2 Pengujian Fungsional

\begin{tabular}{clccc}
\hline No. & \multicolumn{1}{c}{ Komponen } & Tegangan Input & Tegangan Output & Hasil \\
\hline 1 & Mikrokontroler Arduino Uno & $5 \mathrm{~V}$ & $4,45 \mathrm{~V}$ & Berfungsi \\
2 & Buzzer & $5 \mathrm{~V}$ & $4,20 \mathrm{~V}$ & Berfungsi \\
3 & Motor Servo SG90 & $5 \mathrm{~V}$ & $4,45 \mathrm{~V}$ & Berfungsi \\
4 & Ultrasonik HC-SR04 & $5 \mathrm{~V}$ & $4,45 \mathrm{~V}$ & Berfungsi \\
5 & RTC DS3231 & $5 \mathrm{~V}$ & $4,35 \mathrm{~V}$ & Berfungsi \\
\hline
\end{tabular}

Berdasarkan tabel pengujian fungsional diatas menggunakan sumber tegangan input $5 \mathrm{~V}$, yang dialirkan ke komponen elektronik penyusun alat yang telah dirangkai. Tegangan output yang dihasilkan sudah sesuai kebutuhan komponen.

\section{Uji Coba Optimasi}

Pengujian merupakan pengujian sistem atau kinerja alat penjadwal pakan ikan hias koi otomatis. Pengujian ini bertujuan untuk mengetahui letak error yang terjadi saat dilakukan pengujian sehingga bisa ditambahkan pada saran atau kesimpulan penelitian. Alat ini diuji cobakan pada kolam ikan hias koi jenis fiber ukuran $2 \mathrm{~m}$ x 1,5 m dengan populasi ikan 15 ekor.

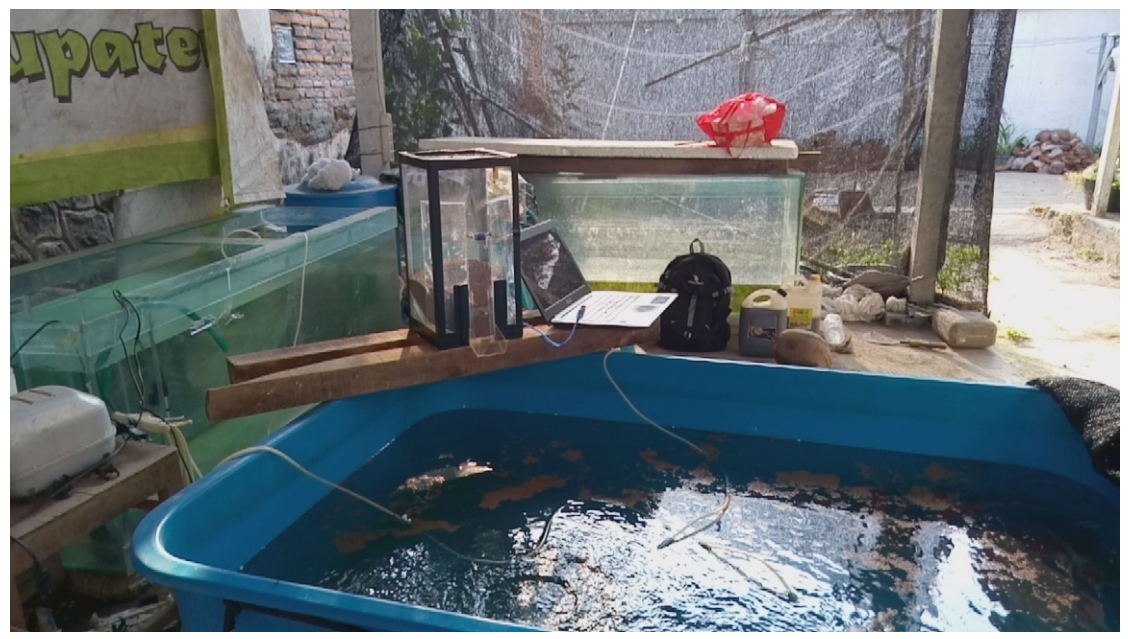

Gambar 5 Pengujian Sistem

\section{Uji Coba Deteksi Pakan}

Persediaan pakan di deteksi oleh sensor ultrasonik berdasarkan jarak pakan dengan sensor. Indikator sebagai tanda persediaan pakan dalam wadah tinggal sedikit menggunakan buzzer. Pada program diatur apabila jarak pakan dengan sensor lebih dari $32 \mathrm{~cm}$ maka buzzer akan bunyi.Untuk mengetahui presentase kesalahan pengukuran dapat dihitung dengan rumus sebagai berikut :

\section{$\frac{(\text { Jarak Pembacaan Sensor - Jarak Sebenarnya) }}{\text { Jarak Pembacaan Sensor }} \times 100$}


ANTIVIRUS: Jurnal Ilmiah Teknik Informatika (p - ISSN: 1978 - 5232; e - ISSN: 2527 - 337X)

Vol. 12 No. 2 November 2018

Tabel 3 Pengujian Deteksi Pakan

\begin{tabular}{|c|c|c|c|c|c|c|}
\hline No. & Hari & Jam & $\begin{array}{c}\text { Jarak } \\
\text { Sebenarnya } \\
(\mathrm{cm})\end{array}$ & $\begin{array}{c}\text { Jarak Sensor } \\
(\mathrm{cm})\end{array}$ & $\begin{array}{c}\text { Error } \\
(\%)\end{array}$ & Buzzer \\
\hline \multirow[t]{3}{*}{1} & Sabtu, 01 September 2018 & 08.00 & 24 & 25 & 4 & Tidak Bunyi \\
\hline & & 11.00 & 24 & 26 & 7,69 & Tidak Bunyi \\
\hline & & 14.00 & 24 & 27 & 11,11 & Tidak Bunyi \\
\hline \multirow[t]{3}{*}{2} & Minggu, 02 September 2018 & 08.00 & 25 & 26 & 3,85 & Tidak Bunyi \\
\hline & & 11.00 & 25 & 26 & 3,85 & Tidak Bunyi \\
\hline & & 14.00 & 25 & 27 & 7,41 & Tidak Bunyi \\
\hline \multirow[t]{3}{*}{3} & Senin, 03 September 2018 & 08.00 & 26 & 28 & 7,14 & Tidak Bunyi \\
\hline & & 11.00 & 26 & 28 & 7,14 & Tidak Bunyi \\
\hline & & 14.00 & 27 & 28 & 3,57 & Tidak Bunyi \\
\hline \multirow[t]{3}{*}{4} & Selasa, 04 September 2018 & 08.00 & 27 & 28 & 3,57 & Tidak Bunyi \\
\hline & & 11.00 & 27 & 29 & 6,90 & Tidak Bunyi \\
\hline & & 14.00 & 29 & 28 & 3,57 & Tidak Bunyi \\
\hline \multirow[t]{3}{*}{5} & Rabu, 05 September 2018 & 08.00 & 29 & 30 & 3,33 & Tidak Bunyi \\
\hline & & 11.00 & 29 & 29 & 0 & Tidak Bunyi \\
\hline & & 14.00 & 30 & 29 & 3,45 & Tidak Bunyi \\
\hline
\end{tabular}

Pengujian sensor dilakukan setiap waktu pemberian pakan ikan koi, pengujian dilakukan selama 5 hari. Selisih jarak terbesar antara jarak sebenarnya dengan jarak sensor adalah $3 \mathrm{~cm}$ dengan presentase error 11,11\%. Penyebab terjadinya error dikarenakan pembacaan sensor kurang stabil yang disebabkan permukaan pakan berubah-ubah dan sensor terlalu dekat dengan pintu keluar.

2. Pengujian Mekanik Buka Tutup

Pengujian ini difokuskan pada buka tutup katup pakan untuk mengetahui lebar pintu pada saat terbuka dan jumlah pakan yang keluar dari wadah sesuai dengan kebutuhan atau tidak. Pengujian ini untuk menentukan lama waktu yang dibutuhkan dalam pemberian pakan dan juga berapa sudut serta lebar pintu katup terbuka, hasil pengujian dapat dilihat pada tabel 4.

\begin{tabular}{|c|c|c|c|c|c|}
\hline $\begin{array}{c}\text { Sudut Motor } \\
\text { Servo }\left({ }^{\circ}\right)\end{array}$ & $\begin{array}{c}\text { Berat Pakan } \\
\text { (gram) } \\
1 \text { Detik }\end{array}$ & $\begin{array}{c}\text { Berat Pakan } \\
\text { (gram) } \\
\text { 2 Detik }\end{array}$ & $\begin{array}{c}\text { Berat Pakan } \\
\text { (gram) } \\
\text { 3 Detik }\end{array}$ & $\begin{array}{c}\text { Berat Pakan } \\
\text { (gram) } \\
\text { 4 Detik }\end{array}$ & $\begin{array}{c}\text { Berat Pakan } \\
\text { (gram) } \\
5 \text { Detik }\end{array}$ \\
\hline $60^{\circ}$ & $25 \mathrm{gr}$ & $38 \mathrm{gr}$ & $50 \mathrm{gr}$ & $60 \mathrm{gr}$ & $65 \mathrm{gr}$ \\
\hline $70^{\circ}$ & $35 \mathrm{gr}$ & $42 \mathrm{gr}$ & $55 \mathrm{gr}$ & $66 \mathrm{gr}$ & $73 \mathrm{gr}$ \\
\hline
\end{tabular}

Berdasarkan uji mekanik buka tutup katup yang dilakukan, peneliti menggunakan sudut $60^{\circ}$ dengan lama waktu bukaan 3 detik. Karena menurut pembudidaya ikan koi, dengan populasi 15 ekor ikan koi hanya membutuhkan pakan sebanyak kurang lebih 50 gram, pengujian pemberian pakan dapat dilihat pada tabel 5 .

\begin{tabular}{lccc}
\multicolumn{4}{c}{ Tabel 5 Pemberian Pakan } \\
\cline { 2 - 4 } Hari & 08.00 & 11.00 & 14.00 \\
& $\checkmark$ & $\checkmark$ & $\checkmark$ \\
Sabtu, 01 September 2018 & $\checkmark$ & $\checkmark$ & $\checkmark$ \\
Minggu, 02 September 2018 & $\checkmark$ & X & $\checkmark$ \\
Senin, 03 September 2018 & $\checkmark$ & $\checkmark$ & X \\
Selasa, 04 September 2018 & $\checkmark$ & $\checkmark$ & X \\
Rabu, 05 September 2018 & $\checkmark$
\end{tabular}

Keterangan : $\checkmark=$ Pakan Keluar, $X=$ Pakan Tidak Keluar 
Secara kesuluruhan alat ini bekerja sesuai program yang diberikan dan sesuai jadwal. Adapun kesalahan yang menyebabkan alat tidak memberi pakan ikan adalah pintu pakan memiliki tuas yang terlalu panjang, dan kesalahan pada penataan jalur pintu.

\subsection{Kesimpulan}

\section{KESIMPUlAN DAN SARAN}

Hasil pengujian dan pembahasan tentang perancangan pakan ikan koi otomatis pada kolam, peneliti dapat menyimpulkan bahwa:

a. Perancangan alat penjadwal pakan koi otomatis berhasil dirancang dan dibuat dengan menggunakan mikrokontroler arduino ATmega 328 sebagai pengendali sistem, yang dilengkapi RTC DS3231 sebagai timer keluarnya pakan dan sensor ultrasonik untuk mendeteksi ketersediaan pakan.

b. Pengujian sistem secara keseluruhan menunjukan bahwa semua komponen mampu menjalankan fungsinya yakni memberi pakan ikan koi ketika jam menunjukan 08.00, 11.00, dan 14.00 dengan sekali bukaan pakan keluar sebanyak 50 gram.

c. Buzzer bunyi ketika sensor membaca jarak pakan lebih dari $32 \mathrm{~cm}$, yang menandakan ketersediaan pakan ikan dalam wadah tinggal sedikit.

4.2 Saran

Perancangan alat pemberian pakan ikan hias koi otomatis pada kolam, diharapkan dapat dikembangkan agar lebih baik lagi kedepanya. Adapun saran yang dapat diberikan oleh penulis adalah sebagai berikut :

a. Agar alat pemberian pakan ikan hias koi dapat diterapkan pada kolam besar bisa ditambahkan motor DC untuk menebar pakan.

b. Indikator persedian pakan bisa diganti menggunakan loudspeaker, sms, led dan lain-lain.

\section{REFERENSI}

[1]Dayat, Muhamad dan Sitanggang, Maloedyn.2004.Budi Daya Koi Blitar: Pengalaman dari Ciganjur.Jakarta: Agromedia Pustaka.

[2]Darmawis. 2017. Alat Pemberi Makan Ikan dan Pendeteksi pH Air pada Kolam Ikan secara Otomatis. Skripsi. Di publikasikan. Padang: Politeknik Negeri Padang.

[3]Setiawan, Dany. 2014. Arduino Uno. www.ilmuti.org.11 Juli 2018.

[4]Maxim Integrated Products. 2010. Extremely Accurate I2C - Integrated RTC/TCXO/Crystal DS3231. 120 San Gabriel Drive : Maxim Integrated Products.inc.

[5]Kurniawan,Muhamad Arie. 2016. Aplikasi Accelerometer Pada Penstabil Monopod Menggunakan Motor Servo. Skripsi. Palembang : Politeknik Negeri Sriwijaya.

[6]Morgan, Elijah J. 2014. HC-SR04 Ultrasonic Sensor. Ebook.

[7] Sugiyono. 2016. Cara Mudah Menyusun Skripsi, Tesis, dan Disertasi (STD). Bandung: ALFABETA. 